\title{
Autonomous acoustic recorders reveal complex patterns in avian detection probability
}

\section{Authors: Sarah J. Thompson, Colleen M. Handel, and Lance B. McNew}

This is the peer reviewed version of the following article: citation below, which has been published in final form at https://dx.doi.org/10.1002/jwmg.21285 This article may be used for non-commercial purposes in accordance with Wiley Terms and Conditions for Self-Archiving.

Thompson, Sarah J., Colleen M. Handel, and Lance B. Mcnew. "Autonomous acoustic recorders reveal complex patterns in avian detection probability." Journal of Wildlife Management 81, no. 7 (September 2017): 1228-1241. DOI: 10.1002/jwmg.21285.

Made available through Montana State University's $\underline{\text { ScholarWorks }}$ scholarworks.montana.edu 


\title{
Autonomous Acoustic Recorders Reveal Complex Patterns in Avian Detection Probability
}

\author{
SARAH J. THOMPSON, ${ }^{1}$ U.S. Geological Survey, Alaska Science Center, 4210 University Drive, Anchorage, AK 99508, USA \\ COLLEEN M. HANDEL, U.S. Geological Survey, Alaska Science Center, 4210 University Drive, Anchorage, AK 99508, USA \\ LANCE B. MCNEW, ${ }^{2}$ U.S. Geological Survey, Alaska Science Center, 4210 University Drive, Anchorage, AK 99508, USA
}

\begin{abstract}
Avian point-count surveys are typically designed to occur during periods when birds are consistently active and singing, but seasonal and diurnal patterns of detection probability are often not well understood and may vary regionally or between years. We deployed autonomous acoustic recorders to assess how avian availability for detection (i.e., the probability that a bird signals its presence during a recording) varied during the breeding season with time of day, date, and weather-related variables at multiple subarctic tundra sites in Alaska, USA, 2013-2014. A single observer processed 2,692 10-minute recordings across 11 site-years. We used time-removal methods to assess availability and used generalized additive models to examine patterns of detectability (joint probability of presence, availability, and detection) for 16 common species. Despite lack of distinct dawn or dusk, most species displayed circadian vocalization patterns, with detection rates generally peaking between 0800 hours and 1200 hours but remaining high as late as 2000 hours for some species. Between 2200 hours and 0500 hours, most species' detection rates dropped to near 0 , signaling a distinctive rest period. Detectability dropped sharply for most species in early July. For all species considered, time-removal analysis indicated nearly $100 \%$ likelihood of detection during a 10-minute recording conducted in June, between 0500 hours and 2000 hours. This indicates that non-detections during appropriate survey times and dates were attributable to the species' absence or that silent birds were unlikely to initiate singing during a 10-minute interval, whereas vocally active birds were singing very frequently. Systematic recordings revealed a gradient of species' presence at each site, from ubiquitous to incidental. Although the total number of species detected at a site ranged from 16 to 27, we detected only 4 to 15 species on $\geq 5 \%$ of the site's recordings. Recordings provided an unusually detailed and consistent dataset that allowed us to identify, among other things, appropriate survey dates and times for species breeding at northern latitudes. Our results also indicated that more recordings of shorter duration (1-4 min) may be most efficient for detecting passerines. (c) 2017 The Wildlife Society.
\end{abstract}

KEY WORDS Alaska, autonomous acoustic recorders, availability, birds, closure, detection probability, subarctic, time-removal.

For avian surveys, the cumulative probability of detecting an individual during a sampling event can be broken down into 4 primary components (Nichols et al. 2009): the probability that the bird's home range overlaps with some part of the survey area $\left(\mathrm{P}_{\mathrm{s}}\right.$, spatial sampling), the probability that a bird is present within the survey area at the time of the sampling event $\left(\mathrm{P}_{\mathrm{p}}\right.$, presence), the probability that a bird is visible or giving vocal cues and therefore can be detected during the sampling event $\left(\mathrm{P}_{\mathrm{a}}\right.$, availability, given presence), and the probability that the observer detects the bird, given that it is present and giving cues $\left(\mathrm{P}_{\mathrm{d}}\right.$, detection, conditional on presence and availability). Most studies attempt to maximize these components of detection probability through appropriate sampling design and training. For example, $\mathrm{P}_{\mathrm{s}}$ and $\mathrm{P}_{\mathrm{p}}$ can be maximized by selecting sample units in specific habitat and of an appropriate size and spatial arrangement for the study goals and species of interest; $\mathrm{P}_{\mathrm{a}}$ can be maximized by conducting surveys during peak seasonal and diurnal periods of singing and territorial displays; and $\mathrm{P}_{\mathrm{d}}$ can be maximized by training observers in visual and aural identification of the species of interest (Nichols et al. 2009).

Many sampling and analytical methods have been developed to estimate these detection parameters statistically, including time-removal models to assess $\mathrm{P}_{\mathrm{a}}$ (Farnsworth et al. 2002), double-observer and distance-sampling 
methods to estimate $\mathrm{P}_{\mathrm{d}}$ (Buckland et al. 1993, Nichols et al. 2000), repeat surveys to estimate combined $P_{a}$ and $P_{p}$ (Royle 2004, Dail and Madsen 2011), or some combination of methods to estimate parameters separately or jointly (Pollock et al. 2002, Amundson et al. 2014). Nonetheless, there is still rigorous debate about how assumptions regarding components of the detection process may be violated and lead to bias when using these methods (Welsh et al. 2013, GuilleraArroita et al. 2014, Hayes and Monfils 2015, Latif et al. 2015) and all methods benefit from survey designs that target consistent and high detection probability (Amundson et al. 2014). Much of what we know about the detection process and how various models perform is based on simulation, and few studies set out explicitly to assess probability of detection or its components in field conditions (MacKenzie et al. 2002, Alldredge et al. 2008).

One component of detection probability, $\mathrm{P}_{\mathrm{a}}$, is an important consideration when planning breeding bird surveys. Songbirds and shorebirds, for the most part, sing or vocally display most ardently and consistently from dawn to late morning, during dates of peak breeding activity, and in mild weather (Robbins 1981, Skirvin 1981, Nebel and McCaffery 2003). Because a large proportion of birds detected during surveys is heard rather than seen, most species have highest availability when singing activity is highest (Brewster and Simons 2009); therefore, most avian surveys are designed to occur during periods of consistent singing activity (Ralph et al. 1998). Few studies have examined avian availability over a wider range of dates or times because most assessments of detection or availability are conducted concurrently with avian surveys designed for a specific purpose, such as estimating density or monitoring changes in abundance (Robbins 1981, Rollfinke and Yahner 1990, Lein 2007). In some instances, it may be valuable to extend surveys to later times of day or later into the breeding season if availability of target species remains reasonably consistent. For example, at high latitudes there is no distinctive sunrise or sunset during mid-summer and, in these regions, birds may maintain reasonably high availability over a longer span of hours than at lower latitudes. Given the short duration of breeding seasons at these latitudes, it would be valuable to be able to extend surveys to include a wider range of dates and times, if appropriate.

Repeated surveys at sampling units can be used to assess availability; when different birds or species are detected at subsequent surveys, models can assess how avian detections relate to time of day or day of season. However, when repeated surveys are undertaken at sampling units, a second component of detection, $\mathrm{P}_{\mathrm{p}}$, becomes of particular interest because birds can move in and out of sampled areas between surveys (Nichols et al. 2009). Such repeated surveys can be designed to answer questions regarding the number of species (or individuals) that use a given sampling unit at some time during the temporal span of the surveys, such as an entire breeding season. This quantity has been termed the superpopulation using the sampling unit (Nichols et al. 2009). The probability of presence of a given individual bird will depend upon the proportion of its territory that overlaps the sampling unit (or time spent there), and probability of presence of a species will be a cumulative function of the number of individuals with territories overlapping the sampling unit. Repeated surveys, then, can provide information on the entire community of birds that uses a particular sampling unit during a defined period of time.

Autonomous acoustic recorders are becoming increasingly affordable and easy to use (Acevedo and Villanueva-Rivera 2006, Sidie-Slettedahl et al. 2015). Autonomous recorders are appealing in that they can be programmed to record data 24 hours a day, either continuously or at specified intervals, for weeks or months at a time; further, all recordings can be permanently archived for future reference (Acevedo and Villanueva-Rivera 2006). Autonomous recorders are unlikely to disrupt bird behavior or influence detection of shy or mobbing species, unlike surveys that require the presence of a human observer (McShea and Rappole 1997, Lee and Marsden 2008). Recordings can be processed in ways that reduce issues that stem from varying observer skill levels. For example, a large number of recordings can be processed by a single observer or multiple observers can listen to the same sets of recordings. Additionally, computer algorithms can be used to process recordings and future developments in this arena may allow for easier or better processing than what is currently available (Rempel et al. 2005). On the other hand, autonomous recorders offer unique challenges such as the production of an overabundance of data and difficulty interpreting bird vocalizations with no visual or spatial reference (e.g., differentiating individual birds).

Despite advances in analytical techniques to account for imperfect detection in traditional point counts (e.g., hierarchical N-mixture models; Royle and Nichols 2003), some issues are still not well addressed and can complicate inference about detection (Alldredge et al. 2008). For example, differences in detection probability among observers constitute a significant source of variation that should be accounted for when estimating population trends or density (Sauer et al. 1994, Farnsworth et al. 2002, Diefenbach et al. 2003). Also, although some methods specifically incorporate false-positive errors, most assume that these errors do not occur, despite evidence that even experienced observers misidentify species (Simons et al. 2007, Miller et al. 2011). Some detection models assume closure, or that no individuals move into or out of the survey area during a survey, or between a series of repeated surveys; this is an assumption that most avian ecologists recognize as problematic (Hayes and Monfils 2015). Recording devices open the door to potentially novel data-processing options or methods that can address or eliminate issues with observer variation, thereby making data more consistent and, in some cases, more reliable than information based on traditional point counts. Further, autonomous recorders can record a long time-span of audio data, which allows for detailed assessments of availability and presence over these long durations. Long recording durations can maximize the likelihood that all species using a sampling unit during a prescribed interval, such as a breeding season, are detected at least once, providing a record of true site use, defined as whether a site 
was ever occupied over a time period of interest (MacKenzie and Royle 2005).

As part of a study of the long-term response of highlatitude landbirds to climate and landscape change in the boreal-tundra ecotone, we deployed autonomous acoustic recorders at fixed locations across subarctic tundra on the Seward Peninsula of Alaska, USA. During 2 summers (2013, 2014), we set devices to record at consistent intervals throughout the breeding season to assess avian detectability across a wide range of time periods. Because systematic audio recordings are similar to repeat survey methods, the recordings assessed a combination of $\mathrm{P}_{\mathrm{p}}, \mathrm{P}_{\mathrm{a}}$, and $\mathrm{P}_{\mathrm{d}}$ (i.e., detectability). In this analysis, we endeavored to isolate $\mathrm{P}_{\mathrm{a}}$ from other components of detection probability. By conducting many hours of recordings over the span of a breeding season at each site, we could definitively identify locations where an individual of a species was sometimes present in the survey area (i.e., $\mathrm{P}_{s}=1$ ). We controlled for variation in $\mathrm{P}_{\mathrm{d}}$ by using a single skilled observer to process all recordings. The observer was allowed to repeat sections of the recording until confident that all species were recorded, allowing us to assume a consistent and high $\mathrm{P}_{\mathrm{d}}$. Finally, $\mathrm{P}_{\mathrm{p}}$ would presumably be random and we did not expect it to be influenced by our variables of interest. Thus, any patterns that we observed in avian detection, we expected to be attributable to variation in availability. Our primary goals in this descriptive study were to assess diurnal and seasonal patterns of avian detectability $\left(\mathrm{P}_{\mathrm{p}} \times \mathrm{P}_{\mathrm{a}} \times \mathrm{P}_{\mathrm{d}}\right)$ to identify optimal times for surveying subarctic breeding birds; estimate availability $\left(\mathrm{P}_{\mathrm{a}}\right)$ of a species for detection, given its presence at a site; and provide insights regarding the importance of presence $\left(\mathrm{P}_{\mathrm{p}}\right)$ of species at survey sites relative to a large number of systematic, repeated samples.

\section{STUDY AREA}

Our study took place on the Seward Peninsula, a subarctic, tundra-dominated land mass in northwestern Alaska that separates the Chukchi and Bering seas. The Seward Peninsula is characterized by several rugged mountain ranges that are bordered by low-lying coastal wetlands and interspersed with broad, poorly drained interior valleys; tongues of boreal coniferous forest extend into the eastern portions of the peninsula and a few stands of deciduous forest occur along major rivers (Kessel 1989). Our 7 study sites, which ranged in elevation from $63 \mathrm{~m}$ to $252 \mathrm{~m}$ (Table 1), spanned $85 \mathrm{~km}$ of latitude and $115 \mathrm{~km}$ of longitude on the southwestern portion of the Seward Peninsula and sampled various natural, non-forested areas across coastal and interior lowlands and uplands. Mesic dwarf-shrub meadows occurred at coastal and interior sites with low topographic relief and were dominated by tussock cottongrass (Eriophorum vaginatum), Bigelow's sedge (Carex bigelowii), and low-growing shrubs (dwarf birch [Betula nana], black crowberry [Empetrum nigrum], bog blueberry [Vaccinium uliginosum], tealeaf willow [Salix pulchra]). Dwarf shrub mat tundra occurred on xeric sites at higher elevations and were dominated by lichen (Cetraria spp., Cladina spp.), prostrate shrubs (black crowberry, dwarf birch, netleaf willow $[S$. reticulata $]$, lingonberry $[V$. vitis-idaea], alpine azalea [Loiseleuria procumbens]), and xeric herbs (entire-leaf mountain avens [Dryas integrifolia]). Shrub thickets dominated by mixtures of dwarf birch, willow (Salix spp.), and alder (Alnus spp.) of low to medium stature $(0.5-2.5 \mathrm{~m})$ occurred on hillsides and in riparian areas across the study area, with tall $(2.5-5 \mathrm{~m})$ stands of willow and alder at our easternmost site bordering the boreal forest transition zone. More extensive descriptions of the study area are available in Kessel (1989) and Thompson et al. (2016).

The climate of the study area was typified by short, cool summers and long, cold, and relatively dry winters (Kessel 1989). The spring of 2013 was cold and delayed with numerous snow events throughout May (weather for 1-21 May 2013: daily temperature $\bar{x}=-3.4^{\circ} \mathrm{C}$, range $=-13$ to $3^{\circ} \mathrm{C}$; total precipitation $=3.5 \mathrm{~cm}$ ), as recorded at the nearest weather station at Nome, Alaska (www.wunderground. com). This contrasted with warmer, drier spring weather in 2014 (same period: daily temperature $\bar{x}=0.6^{\circ} \mathrm{C}$, range $=-7$ to $9^{\circ} \mathrm{C}$; total precipitation $=1.4 \mathrm{~cm}$ ). Because of important differences in spring phenology and bird densities between years, we treated sites with recordings in both years as separate sampling units. Hence, use of site throughout the paper implies a unique combination of location and year unless otherwise specified.

Table 1. Latitude, longitude, and elevation of study sites on the Seward Peninsula in northwestern Alaska, USA, number of 10-minute acoustic recordings of bird vocalizations analyzed from each site in 2013 and 2014, and years for which ambient air temperature data were available. For each site and year with recordings, a single audio recording device was located at the study site.

\begin{tabular}{|c|c|c|c|c|c|c|}
\hline \multirow[b]{2}{*}{ Site } & \multirow[b]{2}{*}{ Latitude (N) } & \multirow[b]{2}{*}{ Longitude (W) } & \multirow[b]{2}{*}{ Elevation (m) } & \multicolumn{2}{|c|}{ No. recordings } & \multirow[b]{2}{*}{ Temperature } \\
\hline & & & & 2013 & 2014 & \\
\hline Bunker Hill & 65.153 & 164.748 & 197 & 180 & & $\mathrm{NA}^{\mathrm{a}}$ \\
\hline Coffee Dome & 65.272 & 164.793 & 180 & 177 & 373 & 2014 \\
\hline Fox River & 64.825 & 163.715 & 63 & & 362 & 2014 \\
\hline Horton Creek & 64.693 & 164.077 & 252 & 163 & 306 & 2014 \\
\hline Livingston Creek & 64.811 & 166.054 & 154 & 131 & & $2013^{\mathrm{b}}$ \\
\hline McAdam Creek & 65.000 & 166.117 & 121 & 175 & 347 & $2013^{\mathrm{b}}, 2014$ \\
\hline Neva Creek & 65.446 & 164.640 & 214 & 149 & 329 & 2014 \\
\hline
\end{tabular}

${ }^{\text {a }}$ No temperature data available.

b Temperature recorders provided data for a subset of audio recordings, with 2013 representing only $7 \%$ of all temperature data. 


\section{METHODS}

\section{Equipment and Data Collection}

We deployed a single Song Meter Digital recorder (Model SM2, Wildlife Acoustics, Maynard, MA, USA) at 6 study sites in 2013 and 5 sites in 2014, 4 of which were sampled in both years. Recorders were set to record for 10 minutes at the start of every hour in 2013 and every other hour in 2014; we reduced the sampling intensity in 2014 because the amount of data collected in 2013 was beyond our processing capability. We deployed recorders as early as possible in late spring and left them in place for the duration of the breeding season. We attached recorders to stationary metal poles $1 \mathrm{~m}$ above the ground. At one site, we attached the recorder to the bole of a small spruce (Picea spp.) tree at a height of $1.5 \mathrm{~m}$. We placed all recorders $\geq 1 \mathrm{~m}$ from tall deciduous vegetation to reduce interference from rustling leaves. We attached foam covers to microphones to reduce the impact of wind and rain on the recordings. Rain in our study area tended to be light and misty and did not interfere heavily with recordings (S. T. Vold, U.S. Geological Survey, personal communication). We checked recorders 1-4 times per season to change batteries and memory cards and to ensure the devices functioned. Recording devices minimized human presence at sites and potential disturbance to birds. All field procedures were also approved by United States Geological Survey Alaska Center Institutional Animal Care and Use Committee (no. 2012-9).

Most recorders were co-located with $\mathrm{HOBO}$ weather monitoring devices (Onset Computer Corporation, Bourne, MA, USA). Three sites had HOBO U30 weather stations (all in 2014), which measured wind speed and direction, relative humidity, and temperature, and 4 sites had HOBO Pendant units (model UA-002-08), which measured temperature and light intensity (2 sites in 2013 and 2 in 2014). We set weather monitors to record weather data every 30 minutes throughout the day for the duration of the audio recording period. For analysis, we selected the weather measurement taken at the time closest to the beginning of the 10-minute audio recording. If there was not a weather recording within 1 hour of the start of the recording, we did not associate weather data with the recording.

One skilled observer processed a systematic subsample of audio data (Figs. S1 and S2, available online in Supporting Information). We endeavored to process recordings systematically and regularly from sites, dates, and hours, although we were hindered by occasional equipment failure and the logistics involved in simultaneously setting up devices at remote locations. The observer recorded species, minute within the 10-minute sound file during which an individual of that species was first detected, and for a subset of data, the type of vocalization (full song, partial song, call, winnowing flight display). We counted an individual bird only once per recording, whether we heard it a single time or if it vocalized repeatedly. When the observer heard multiple individuals of the same species vocalizing, he recorded them as separate entries only if he detected the vocalizations simultaneously or near-simultaneously (e.g., counter-singing male). The observer replayed segments of the recording as needed, particularly if numerous birds were singing or when there were distracting or difficult-to-identify noises. The observer was allowed to listen as many times as necessary and was able to refer to other resources, including online bird sound libraries or other bird song experts when processing recordings. Because most detections were singing males, a single detection of a species would represent $\geq 2$ individuals in most cases (i.e., a breeding pair). Occasionally, the observer noted that a recorder may have tipped over or was not correctly functioning; we omitted these surveys from analysis. Some recordings lasted only 5 minutes because of equipment malfunction; we also omitted these surveys. For analysis, we combined hoary (Acanthis hornemanni) and common redpolls (A. Alammea) because it was difficult to separate these species by sound alone.

\section{Statistical Analysis}

We were interested in analyzing variation in detectability (combined $\mathrm{P}_{\mathrm{p}} \times \mathrm{P}_{\mathrm{a}} \times \mathrm{P}_{\mathrm{d}}$ ) at sites where a species was known to be at least an occasional occupant or user (i.e., $P_{s}=1$ ). After initial inspection of the data, we defined a site to be occupied by a given species when $\geq 1$ individual was detected in $\geq 5 \%$ of processed recordings and we omitted sites where detection frequencies were below this threshold to minimize the effect of species with tenuous ties to a location. Species detected less frequently might be migrating birds, nonresident unpaired males, or dispersing young of the year, and we did not want to include these in our assessments of vocalization patterns. We selected the $5 \%$ threshold after exploring a variety of values between 0 and $15 \%$ of recordings and seeing little change in overall patterns of detection as we added or removed sites. When modeling effects of covariates on patterns of detectability for a given species (see below), we omitted any recordings that took place before the first detection of the species each year to assure that the species was present and potentially available to be detected on the study area. Because of challenges associated with discerning $>1$ individual of a species, we reduced count data to 1 or 0 (i.e., species detected or not detected) for each recording.

We analyzed diurnal and seasonal variation in detection or non-detection (i.e., 1 or 0 ) using generalized additive models (GAM) with a binomial error structure and logit link function ( $\mathrm{R}$ statistical software, version 3.2.3 and $\mathrm{R}$ package mgcv; R Development Core Team 2015, Wood 2016). We anticipated that patterns of detection would be complex and not well fit by quadratic or cubic terms in a generalized linear model, and opted for generalized additive models because of their ability to fit complex curves. These models examined the joint probability of presence, availability, and detection (i.e., detectability or detection probability) of a given species at occupied sites relative to date, time of day, and ambient temperature. The area effectively sampled by the recording devices varied for each species depending on the intensity and frequency (i.e., $\mathrm{Hz}$ ) of the species' vocalizations, moderated by vegetation and sometimes weather, especially wind, at the sites (Schieck 1997). We assumed that variation in $P_{p}$ and $P_{d}$ at a given site was random relative to the covariates of interest 
(date, time of day, temperature) and we controlled for observer-related variation in $\mathrm{P}_{\mathrm{d}}$ by using a single observer to analyze all recordings. Thus, this analysis was focused on exploring variation in $\mathrm{P}_{\mathrm{a}}$ relative to the covariates, not its absolute value.

In the GAM analysis for each species, we first considered a single model that included hour of day (0-23) and chronological day of season (1-63 where $1=25$ May); we fit both with smooth functions and restricted models to $\leq 6$ degrees of freedom to avoid overfitting. For hour of day, which is a cyclic variable, we also included a cyclic cubic regression spline to make 0000 hours and 2400 hours meet. We included the relative abundance of singing males recorded at a site (i.e., simultaneously vocalizing birds) as a continuous parametric model component (i.e., a linear term, not fit with a smooth function) to account for varying density of each species, which we expected to have a strong effect on probability of detection (Royle and Nichols 2003). We derived this number by locating the maximum number of simultaneously vocalizing birds recorded for each site on any recording. We omitted site as a fixed effect because relative abundance of the species was a more informative factor influencing detection and it covaried with site. Additionally, site was a poor random effect because some less common species occurred at a small number of sites (i.e., a random effect may have only 1-3 levels in some instances; Zuur et al. 2007). When generating model-based predictions, we always fixed the relative abundance value to 2 ; when varying hour for predictions, we fixed day of season at 25 (18 Jun); and when varying date for predictions, we fixed hour at 0900 hours. We presumed that diurnal patterns would be consistent between years but that seasonal patterns could vary annually because of different spring weather and phenology. To assess how seasonal patterns of detection varied by year, we ran the same model for a subset of species with sufficient sample sizes, separating data from 2013 and 2014. Similarly, we were interested in exploring how diurnal patterns of detection varied throughout the season. Because GAMs do not accommodate interactive terms, we again split data into seasonal intervals for a number of species, based on their biology, and generated predictions of 24-hour detection patterns for each seasonal interval. Finally, after discarding suspicious weather data (repeated identical readings or anomalously high or low readings), 5 sites had temperature data for most recordings and 2 others had limited temperature data (Table 1). We examined the marginal effect of temperature on detectability by adding a smooth term for temperature $\left({ }^{\circ} \mathrm{C}\right)$ to the previously described date and hour model.

We conducted a separate analysis using the removal model, which estimates $\mathrm{P}_{\mathrm{a}}$ by analyzing the time within a survey when a species or individual was first detected (Farnsworth et al. 2002). We estimated the probability of detecting a species during a 10-minute recording, given that the species was present, assuming closure to movement in and out of the sampling area during that short interval. This method is not informed by surveys where a species was never observed and thus did not require assumptions regarding occupancy as in the previous analysis. This method attempts to account for instances where individuals (in our case, species) are present but silent. However, removal methods are likely challenged by the tendency of many bird species to sing in bursts, such that detection during an interval is not independent of other intervals during a survey. For each recording, we located the minute during which a species was first detected, generating 0 s for intervals before that minute, a 1 when the species was first detected, and NAs for subsequent minutes (Kéry and Royle 2015:621). We conducted the analysis with R statistical software, using the library unmarked to run a hierarchical occupancy model (MacKenzie et al. 2002, Fiske and Chandler 2011, R Development Core Team 2015, Kéry and Royle 2015). These models were not able to accommodate high-order polynomials (i.e., cubic terms caused model failures). Thus, we included hour of day and day of season as

Table 2. Species observed, number of 10-minute recordings on which the species was present $(\geq 1$ individual detected per recording) among 2,692 total recordings, and the number of sites at which we detected the species. We collected recordings at 11 sites during May-July of 2013 and 2014 on the Seward Peninsula in northwestern Alaska, USA.

\begin{tabular}{|c|c|c|}
\hline Common name & Present & Sites \\
\hline Canada goose & 40 & 9 \\
\hline Tundra swan (Cygnus columbianus) & 8 & 1 \\
\hline Willow ptarmigan & 489 & 10 \\
\hline Rock ptarmigan (Lagopus muta) & 8 & 3 \\
\hline Sandhill crane (Grus canadensis) & 34 & 5 \\
\hline American golden-plover & 135 & 9 \\
\hline Pacific golden-plover & 77 & 9 \\
\hline Whimbrel & 149 & 7 \\
\hline Bristle-thighed curlew (Numenius tabitiensis) & 14 & 3 \\
\hline Surfbird (Calidris virgata) & 1 & 1 \\
\hline Western sandpiper (Calidris mauri) & 36 & 2 \\
\hline Wilson's snipe & 783 & 11 \\
\hline Long-tailed jaeger & 70 & 10 \\
\hline Glaucous gull (Larus hyperboreus) & 1 & 1 \\
\hline Rough-legged hawk (Buteo lagopus) & 14 & 1 \\
\hline Merlin (Falco columbarius) & 2 & 1 \\
\hline Gray jay (Perisoreus canadensis) & 6 & 1 \\
\hline Common raven & 36 & 10 \\
\hline Horned lark (Eremophila alpestris) & 5 & 1 \\
\hline Boreal chickadee (Poecile hudsonicus) & 17 & 1 \\
\hline Ruby-crowned kinglet (Regulus calendula) & 58 & 1 \\
\hline Arctic warbler & 308 & 6 \\
\hline Bluethroat & 268 & 8 \\
\hline Northern wheatear (Oenanthe oenanthe) & 5 & 1 \\
\hline Gray-cheeked thrush & 936 & 10 \\
\hline American robin & 255 & 7 \\
\hline Varied thrush (Ixoreus naevius) & 138 & 1 \\
\hline American pipit (Anthus rubescens) & 78 & 2 \\
\hline Pine grosbeak (Pinicola enucleator) & 4 & 1 \\
\hline Hoary and common redpoll & 1,411 & 11 \\
\hline Lapland longspur & 638 & 9 \\
\hline Northern waterthrush & 187 & 2 \\
\hline Orange-crowned warbler & 217 & 10 \\
\hline Yellow warbler & 348 & 6 \\
\hline Blackpoll warbler (Setophaga striata) & 114 & 3 \\
\hline Yellow-rumped warbler (Setophaga coronata) & 88 & 2 \\
\hline Wilson's warbler & 211 & 6 \\
\hline American tree sparrow & 493 & 7 \\
\hline Savannah sparrow & 1,251 & 11 \\
\hline Fox sparrow & 883 & 11 \\
\hline White-crowned sparrow & 273 & 7 \\
\hline Golden-crowned sparrow & 674 & 9 \\
\hline
\end{tabular}


quadratic terms and maximum bird count as a linear term in the detection portion of the model; we included no covariates in the occupancy portion of the model. All relevant data and code to replicate analyses within this paper are available at https://doi.org/10.5066/F7B856KG.

\section{RESULTS}

One observer processed 2,692 10-minute recordings from 11 sites, during which he detected 43 species on $0.3-88.9 \%$ of recordings (Tables 1 and 2). Of 12,907 bird sounds with information about the vocalization type, $78 \%$ were full or partial songs, $3 \%$ were winnowing displays, and $18 \%$ were calls. The majority of passerine detections were based on full or partial songs throughout the season; calls made up a considerable portion of detections of gray-cheeked thrush (Catharus minimus; 42\%), Lapland longspur (Calcarius lapponicus; 33\%), and American robin (Turdus migratorius; $25 \%)$. Unidentifiable calls were not commonly detected on recordings, either because the recorders did not excel at picking them up, or because the suite of species at our sites has relatively identifiable calls. Among 20 species detected on $\geq 40$ recordings, an average of $48 \pm 2.9 \%$ ( $\mathrm{SE}$; range $=$ $19-65 \%)$ of the initial detections occurred during the first minute of the recording and almost all $(79 \pm 1.4 \%$, range $=66-87 \%$ ) occurred within the first 5 minutes (Table 3 ).

\section{Effects of Date and Time on Detection Probability}

The first processed recordings took place on 25 May in both years, after many species had already settled on territories. Warbler species were an exception, with many first seasonal detections happening days or weeks after the earliest 2014 recordings (Fig. 1). In 2013, a cold and snowy spring, first detections of many warbler species occurred at much later dates compared to 2014 (Fig. 1).

Maximum predicted detection probabilities $\left(\mathrm{P}_{\mathrm{p}} \times \mathrm{P}_{\mathrm{a}} \times \mathrm{P}_{\mathrm{d}}\right)$ from GAMs ranged from $0.34(95 \% \mathrm{CI}=0.21-0.48)$ for white-crowned sparrow (Zonotrichia leucophrys) to 0.93 (0.90-0.97) for arctic warbler (Phylloscopus borealis) during the season (Table 4). Models predicted that, for many species, dates of high detectability began soon after a species was first detected (i.e., immediately after first detection or during the earliest recordings of the year), then gradually declined throughout the season (e.g., Wilson's snipe [Gallinago delicata] and American robin; Fig. 2). For several species, detectability increased during the first week of recordings or first week after initial detections (e.g., bluethroat [Luscinia svecica], gray-cheeked thrush, and yellow warbler [Setophaga petechia]; Fig. 2). Most warblers and sparrows maintained near-maximum detection rates for several weeks, beginning soon after arrival and lasting for roughly 30 days, then steeply dropping during early July, around day 40 (e.g., orange-crowned warbler [Oreothlypis celata], Wilson's warbler [Cardellina pusilla], and Savannah sparrow [Passerculus sandwichensis]; Fig. 2). The seasonal detection patterns for American tree sparrow (Spizelloides arborea) and redpolls were anomalous; detection probability increased until reaching its highest estimate late in the season on 26 June and 6 July, respectively (Fig. 2, Table 4).
Table 3. Distribution of times of first detection during 10-minute recordings for 20 species of birds that were detected on $\geq 40$ recordings. Initial columns indicate the proportion of first detections that occurred during each of the first 5 minutes and during the last 5 minutes combined (6-10 min). Results are based on 2,692 recordings, collected at 11 sites during May-July of 2013 and 2014 on the Seward Peninsula in northwestern Alaska, USA.

\begin{tabular}{lcccccc}
\hline & \multicolumn{7}{c}{ Minutes } \\
\cline { 2 - 7 } Species & $\mathbf{1}$ & $\mathbf{2}$ & $\mathbf{3}$ & $\mathbf{4}$ & $\mathbf{5}$ & $\mathbf{6 - 1 0}$ \\
\hline Willow ptarmigan & 0.43 & 0.16 & 0.10 & 0.06 & 0.05 & 0.22 \\
American golden-plover & 0.24 & 0.10 & 0.13 & 0.07 & 0.13 & 0.33 \\
Whimbrel & 0.19 & 0.15 & 0.10 & 0.10 & 0.11 & 0.34 \\
Wilson's snipe & 0.47 & 0.14 & 0.07 & 0.08 & 0.06 & 0.19 \\
Arctic warbler & 0.60 & 0.09 & 0.07 & 0.05 & 0.04 & 0.15 \\
Bluethroat & 0.35 & 0.14 & 0.08 & 0.10 & 0.06 & 0.28 \\
Gray-cheeked thrush & 0.59 & 0.09 & 0.07 & 0.06 & 0.05 & 0.14 \\
American robin & 0.37 & 0.14 & 0.08 & 0.09 & 0.06 & 0.27 \\
Common and hoary redpoll & 0.37 & 0.14 & 0.11 & 0.09 & 0.06 & 0.24 \\
Lapland longspur & 0.50 & 0.11 & 0.08 & 0.05 & 0.04 & 0.22 \\
Northern waterthrush & 0.65 & 0.09 & 0.05 & 0.03 & 0.05 & 0.13 \\
Orange-crowned warbler & 0.50 & 0.08 & 0.09 & 0.07 & 0.06 & 0.20 \\
Yellow warbler & 0.51 & 0.10 & 0.08 & 0.05 & 0.08 & 0.18 \\
Blackpoll warbler & 0.58 & 0.09 & 0.05 & 0.07 & 0.04 & 0.17 \\
Wilson's warbler & 0.63 & 0.05 & 0.04 & 0.07 & 0.07 & 0.15 \\
American tree sparrow & 0.39 & 0.12 & 0.09 & 0.07 & 0.06 & 0.27 \\
Savannah sparrow & 0.54 & 0.12 & 0.07 & 0.06 & 0.05 & 0.17 \\
Fox sparrow & 0.57 & 0.09 & 0.07 & 0.06 & 0.04 & 0.17 \\
White-crowned sparrow & 0.40 & 0.14 & 0.10 & 0.08 & 0.08 & 0.22 \\
Golden-crowned sparrow & 0.63 & 0.08 & 0.06 & 0.06 & 0.05 & 0.13 \\
\hline
\end{tabular}

We analyzed recordings for arctic warbler, Wilson's warbler, fox sparrow (Passerella iliaca), yellow warbler, Lapland longspur, and Savannah sparrow separately for 2013 and 2014 to examine interannual patterns of detectability for species with sufficient sample sizes. Most species demonstrated similar patterns between years (Fig. 3). Detection rates declined at similar times in both years for some species (e.g., Wilson's warbler, days 30-40) and for others detection remained high for a longer time period in 2014 (yellow warbler), or underwent a second pulse (e.g.,

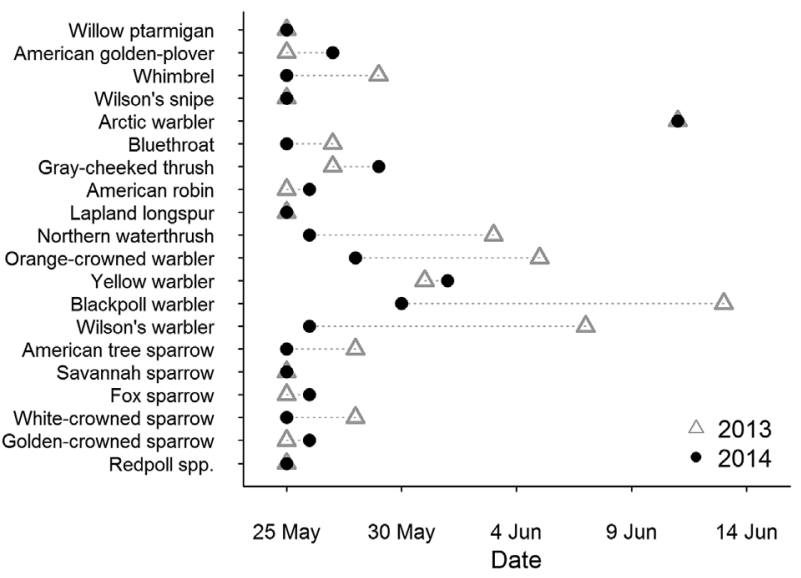

Figure 1. Earliest detections of 20 commonly detected bird species in northwestern Alaska, USA, in 2013 (gray triangles) and 2014 (black circles) by autonomous acoustic recorders. Earliest recordings in both years took place on 25 May. 
Table 4. Predicted probabilities of detecting a given species during a 10-minute acoustic recording at 2 points in time during the sampling period (25 May-21 Jul): on the day of season ( $1=25$ May) and at the hour of day with the maximum predicted detection probability $(\mathrm{P})$ for each species; and on day 25 (18 Jun) at 0900 hours, which our results suggest would be an optimal survey time and date for many species within the avian community. Predictions are based on generalized additive models of 2,692 recordings collected systematically across the season at 11 sites during 2013 and 2014 in northwestern Alaska, USA. Repeated recordings provide a joint detection probability of presence, availability, and detection for species at the sites at which they were considered to be a site user (i.e., occurred on $>5 \%$ of all recordings at that site).

\begin{tabular}{|c|c|c|c|c|c|c|}
\hline \multirow[b]{2}{*}{ Species } & \multicolumn{4}{|c|}{ Maximum for species } & \multicolumn{2}{|c|}{ Optimal for community } \\
\hline & $\mathbf{P}$ & $95 \% \mathrm{CI}$ & Hour & Day & $\mathbf{P}$ & 95\% CI \\
\hline Willow ptarmigan & 0.828 & $0.759,0.898$ & 0400 & 1 & 0.127 & $0.084,0.169$ \\
\hline Wilson's snipe & 0.740 & $0.664,0.816$ & 0900 & 1 & 0.450 & $0.386,0.514$ \\
\hline Arctic warbler & 0.927 & $0.889,0.966$ & 0900 & 29 & 0.960 & $0.868,0.960$ \\
\hline Bluethroat & 0.658 & $0.567,0.749$ & 0900 & 9 & 0.179 & $0.072,0.179$ \\
\hline Gray-cheeked thrush & 0.598 & $0.495,0.702$ & 0100 & 21 & 0.554 & $0.443,0.664$ \\
\hline American robin & 0.622 & $0.509,0.736$ & 0900 & 1 & 0.377 & $0.294,0.461$ \\
\hline Common and hoary redpoll & 0.716 & $0.637,0.794$ & 0900 & 40 & 0.526 & $0.439,0.612$ \\
\hline Lapland longspur & 0.855 & $0.794,0.916$ & 1000 & 1 & 0.281 & $0.212,0.350$ \\
\hline Orange-crowned warbler & 0.710 & $0.616,0.804$ & 0900 & 25 & 0.710 & $0.616,0.804$ \\
\hline Yellow warbler & 0.890 & $0.842,0.938$ & 0900 & 25 & 0.890 & $0.842,0.938$ \\
\hline Wilson's warbler & 0.784 & $0.692,0.876$ & 0900 & 20 & 0.772 & $0.672,0.871$ \\
\hline American tree sparrow & 0.654 & $0.580,0.729$ & 0900 & 33 & 0.607 & $0.526,0.688$ \\
\hline Savannah sparrow & 0.785 & $0.713,0.857$ & 0900 & 1 & 0.711 & $0.653,0.768$ \\
\hline Fox sparrow & 0.686 & $0.628,0.743$ & 0900 & 12 & 0.613 & $0.549,0.676$ \\
\hline White-crowned sparrow & 0.344 & $0.210,0.479$ & 0500 & 1 & 0.197 & $0.132,0.262$ \\
\hline Golden-crowned sparrow & 0.544 & $0.451,0.638$ & 0700 & 31 & 0.517 & $0.421,0.614$ \\
\hline
\end{tabular}

Savannah sparrow) in 2014 that was not observed during the delayed breeding season of 2013 (Fig. 3).

Several distinctive patterns emerged in detection probability predicted over the 24 -hour cycle, as illustrated for midseason (18 Jun; Fig. 4). Many species had consistent and high detectability that lasted for many hours of the day, often remaining high until as late as 2000 hours (arctic warbler, orange-crowned warbler, yellow warbler, Wilson's warbler, Savannah sparrow). Nearly all species displayed a resting period where detection probability dropped to near 0 , typically between the hours of 2200 and 0500 . Many species reached their maximum detectability as they came out of this resting period, often with peak detection predictions between 0700 hours and 1000 hours. Notable exceptions included gray-cheeked thrush, which had high detectability throughout the entire 24-hour cycle and peaked at 0100 hours, and willow ptarmigan (Lagopus lagopus), which vocalized least frequently between 1000 hours and 2000 hours and peaked in detectability at 0400 hours (Fig. 4).

Diurnal patterns varied slightly for some species across the season (Fig. S3, available online in Supporting Information). Variation in amplitude of detectability reflected seasonal changes in vocalization rates (e.g., strong decline in detections of willow ptarmigan and Lapland longspur) or presence on sites (e.g., low detectability of yellow warblers early in season). Some species showed changes in the shapes of the detectability curves across the season. For example, several species (yellow warbler, golden-crowned sparrow [Zonotrichia atricapilla], fox sparrow) showed an increasing bimodality of detections (peaks in morning and evening) later in the season. Sparrows, in particular, showed little variation between early and late season detection patterns (Fig. S3).

Although the date and time of maximum detectability varied among species, surveys conducted at 0900 hours on 16 June (day 25) were predicted to provide optimal detectability for the greatest proportion of the 16 species considered (Table 4). A survey at this date and time would have occurred after the seasonal peak for early species (e.g., willow ptarmigan, Wilson's snipe, American robin, Lapland longspur) but would have assured that late-arriving species (e.g., arctic warbler, gray-cheeked thrush, yellow warbler) were present and available to be detected.

\section{Effects of Relative Abundance and Temperature on Detection Probability}

The likelihood of detecting $\geq 1$ individual for most species was strongly associated with estimated local abundance, as expected (Fig. S4, available online in Supporting Information). When the number of birds detected vocalizing at a site increased from 1 to 2 individuals, models predicted that detectability increased dramatically for some species (e.g., increasing from 0.14 [95\% CI $=0.07-0.22]$ to $0.57[0.46-0.68]$ for gray-cheeked thrush). Among the species considered, bluethroat detectability was the only species not significantly influenced by the number of birds at the site. Every site had a maximum of 2 American robins detected during a season, so we could not estimate detection probability for sites with varying abundance and thus dropped the term from this model.

After accounting for date and time of day, detectability was negatively associated with increasing ambient air temperature for Wilson's snipe, American tree sparrow, Savannah sparrow, and golden-crowned sparrow and positively associated with ambient air temperature for arctic warbler, American robin, Wilson's warbler, and white-crowned sparrow (Fig. S5, available online in Supporting Information). Temperature was not a strong predictor for detectability of the other 8 species.

\section{Estimates of Availability, Given Presence}

When a species was detected on a recording, about half of these detections occurred within the first minute (Table 3). 

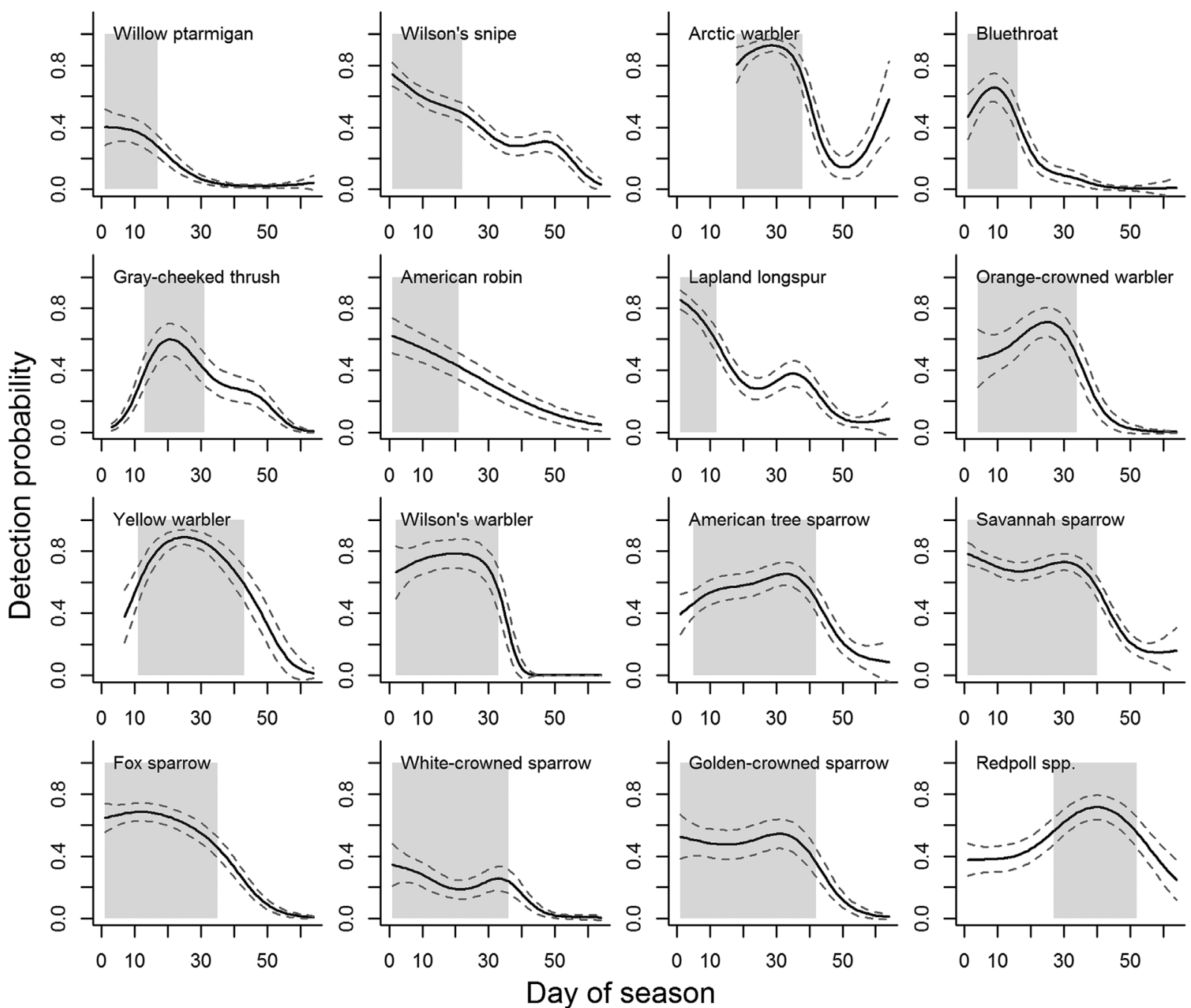

Figure 2. Model-based predictions and $95 \%$ confidence intervals of detection probability for 16 commonly observed bird species by chronological day of season (day 1 = 25 May), May-July 2013-2014, northwestern Alaska, USA. The $y$-axis represents the probability of detecting $\geq 1$ individual of a species during a 10minute recording at a fixed time of day $(0900 \mathrm{hr}$ ) at sites where the species was considered a site user (i.e., occurred on $>5 \%$ of all recordings at that site). The shape of the detection curve reflects the relative availability $\left(\mathrm{P}_{\mathrm{a}}\right)$ during the season for each species. Gray blocks highlight periods encompassing the top 35th percentile of predicted detection probabilities.

However, there was marked variation between species with $19 \%$ of whimbrel (Numenius phaeopus) versus 65\% of northern waterthrush (Parkesia noveboracensis) initial detections occurring during the first 60 seconds. For all 16 species, time-removal analysis predicted nearly 100\% likelihood of availability for detection during any 10-minute survey conducted during June (days 9-36) between 0500 hours and 2000 hours, which would then constitute the optimal survey period (Fig. 5).

\section{Frequency of Detection Relative to Seasonal Occurrence} The cumulative occurrence of species varied widely by site and year; we detected some species at some sites on nearly every recording, whereas others were detected only once in as many as 60 hours of recordings. For each site and year, we sorted detected species into 4 categories: rarely $(0-5 \%$ of recordings), infrequently (6-15\%), commonly (16-50\%), and frequently detected (>50\%; Fig. 6). At individual sites, $36-55 \%$ of all the species detected during the season were categorized as rarely detected, whereas only $5-19 \%$ of species per site were frequently detected (Fig. 6; and Fig. S6, available online in Supporting Information). Detections of species that rarely occurred at a site were not strongly associated with early or late periods of the breeding season but occurred throughout the span of recording dates.

\section{DISCUSSION}

Autonomous acoustic recorders allowed us to record and process a large amount of data on occurrence of birds at specific sites in an unusually homogeneous manner, relaxing constraints that are typically imposed on avian surveys by limited availability of skilled observers and short breeding seasons, especially at northern latitudes (Acevedo and VillanuevaRivera 2006). Our results suggest that detection probabilities of many species of birds breeding in northwestern Alaska remained near their maximum throughout a substantial portion of the breeding season (1-30 Jun) and throughout 

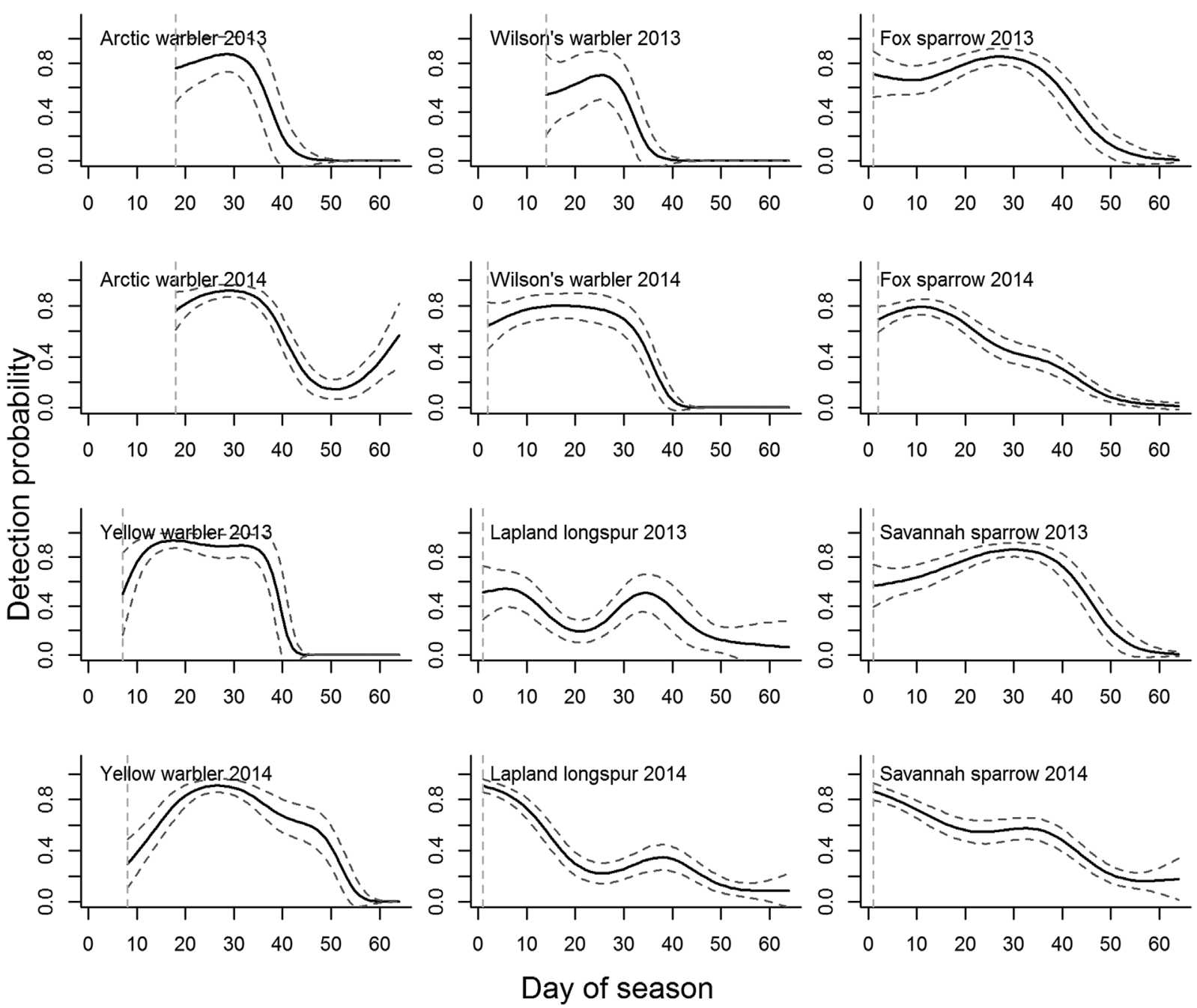

Figure 3. Model-based predictions and $95 \%$ confidence intervals (based on generalized additive models) of detection probability for 6 commonly observed bird species by chronological day of season (day $1=25$ May), May-July 2013-2014, northwestern Alaska, USA, with data split by year. The $y$-axis represents the probability of detecting $\geq 1$ individual of a species during a 10-minute recording at a fixed time of day ( 0900 hours) at sites where the species was a site user. The shape of the detection curve reflects the relative availability $\left(\mathrm{P}_{\mathrm{a}}\right)$ during the season for each species. Vertical gray line denotes the first observation of the species for that year.

most of the day (0500-2000 hours). During these optimal periods, time-removal analysis indicated that for most species considered, availability for detection $\left(\mathrm{P}_{\mathrm{a}}\right)$ was $99-100 \%$ during a single 10-minute recording, suggesting that failure to detect a species during a given recording was due to its temporary absence from the sampling site rather than its failure to vocalize. One of the assumptions of removal models, however, is that individuals with lower detectability have a constant perminute probability of being detected (Farnsworth et al. 2002). If some birds vocalize in bursts interspersed with long rest periods, silent individuals could be missed and availability overestimated.

Despite a lack of dawn or dusk, we observed complex circadian patterns of detectability for subarctic-breeding bird species. We found that singing activity essentially ceased between 2200 hours and 0500 hours for most species; this time period corresponds closely with observations of reduced physical activity, reduced singing behavior, increased time spent resting, and increased melatonin concentrations in other subarctic-breeding bird populations (Silverin et al. 2009, Ashley et al. 2013, Steiger et al. 2013). We observed relatively high detection rates over a broad range of hours for many species, in many instances stretching later into the day than is commonly recommended for surveying. This could be the result of birds at high latitudes singing or displaying more consistently throughout the 24-hour cycle, possibly in response to the weak signal of familiar triggers (consistent daylight, less distinctive temperature reduction at night). Additionally, our metric, detection of $\geq 1$ individual within a 10 -minute recording may have been permissive, tending to detect a species even when singing or calling activity was relatively low (Lynch 1995). The peak time of detection for most species took place in the late morning $(\sim 0900-1000$ hours). Only 2 species were exceptions: willow ptarmigan and gray-cheeked thrush, which had peak detection periods earlier in the morning. These species may have been endeavoring to take advantage of a quiet soundscape while other birds rested, or, possibly, the analyst could more easily 

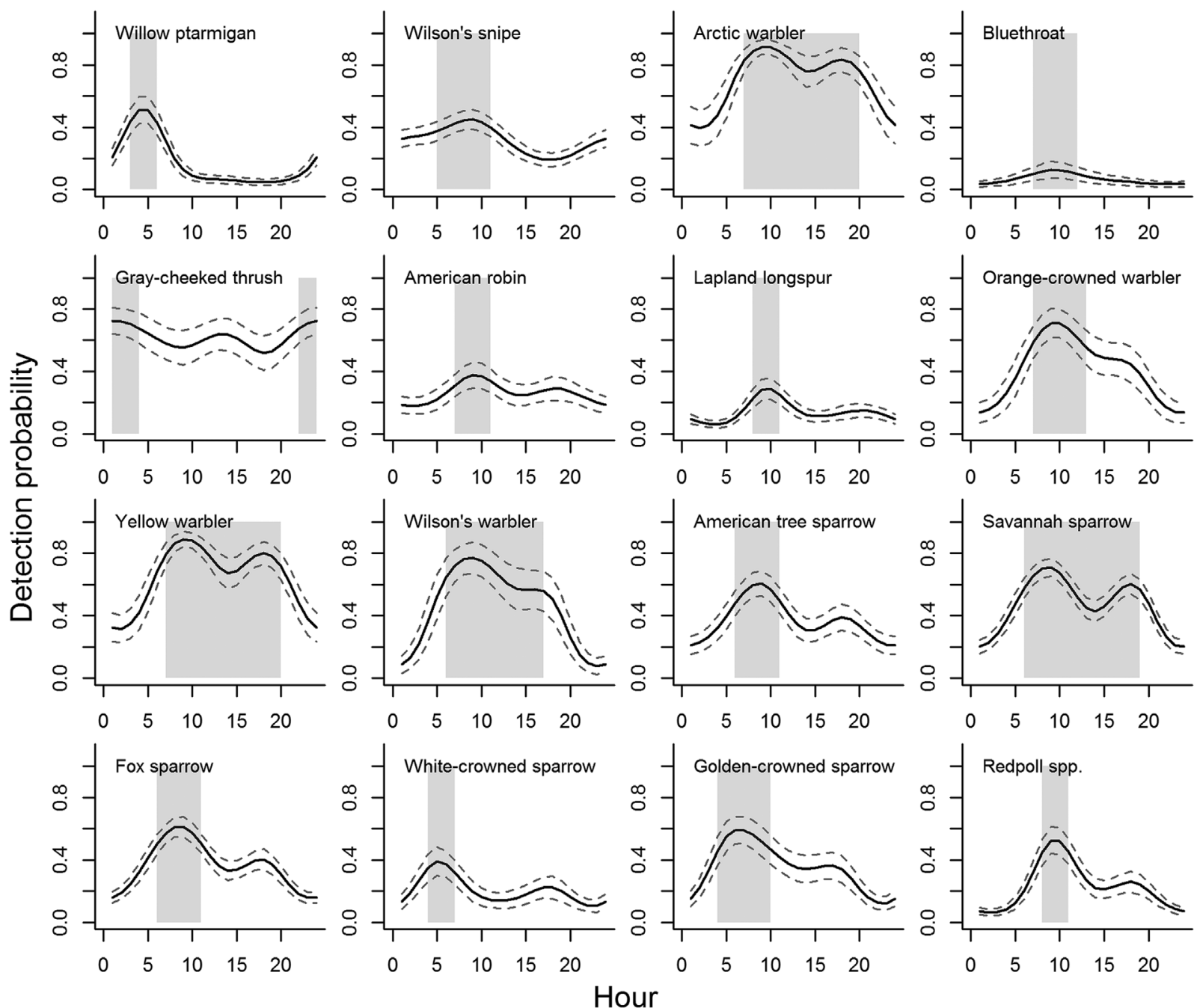

Figure 4. Model-based predictions and $95 \%$ confidence intervals of detection probability for 16 commonly observed bird species by time of day in northwestern Alaska, USA, May-July 2013-2014. The $y$-axis represents the probability of detecting $\geq 1$ individual of a species during a 10-minute recording on a fixed date (18 Jun, day 25) at sites where the species was a site user. The shape of the detection curve reflects the relative availability $\left(\mathrm{P}_{\mathrm{a}}\right)$ during the day for each species. Gray blocks highlight periods encompassing the top 35th percentile of predicted detection probabilities for each species.

detect these species when other birds were silent (SidieSlettedahl et al. 2015); however, the latter is unlikely in our case because both species are loud and distinctive.

We would expect diurnal patterns of detection probability to be consistent between years, but seasonal patterns could vary as a result of different breeding phenology (Smith et al. 2010, Pereyra 2011). Our results suggested that detection patterns were relatively consistent between years; for most species, in both years detection probability was highest soon after arrival and generally waned at about the same time each season. This pattern was particularly notable for Wilson's warblers; despite arriving nearly 10 days later in 2013, detection rates dropped to near 0 by day 40 in both years. Wilson's warblers begin singing upon arrival and cease when young fledge; presuming individuals form pairs and begin nesting immediately, this species requires a minimum of 30 days for egg laying, incubating, and tending hatchlings (Ammon and Gilbert 1999). The span of approximately 20 days of singing in 2013 would not have allowed sufficient time for these activities. Thus, we suspect that some species or individuals likely forewent breeding or did not successfully produce offspring during the late season of 2013. In 2014, several species demonstrated a slight increase in detectability later in the season that was not observed in 2013 (yellow warbler, day 50; fox sparrow, day 40; Savannah sparrow, day 35). This may have been due to detections of hatch-year birds attempting to sing after adults had largely left breeding territories (C. M. Handel, U.S. Geological Survey, unpublished data). Conversely, adults may have initiated a secondary pulse of singing after failed or successful nesting or after offspring fledged (Wilson and Bart 1985, Lowther et al. 1999).

With 23 hours to 60 hours of processed recordings for each site and year, our data also gave us a detailed look at patterns of site use over the duration of a breeding season. At each site, we observed a gradient from rare to nearly ubiquitous site users. Species that were detected frequently or regularly at a site most certainly had $\geq 1$ individuals with established 


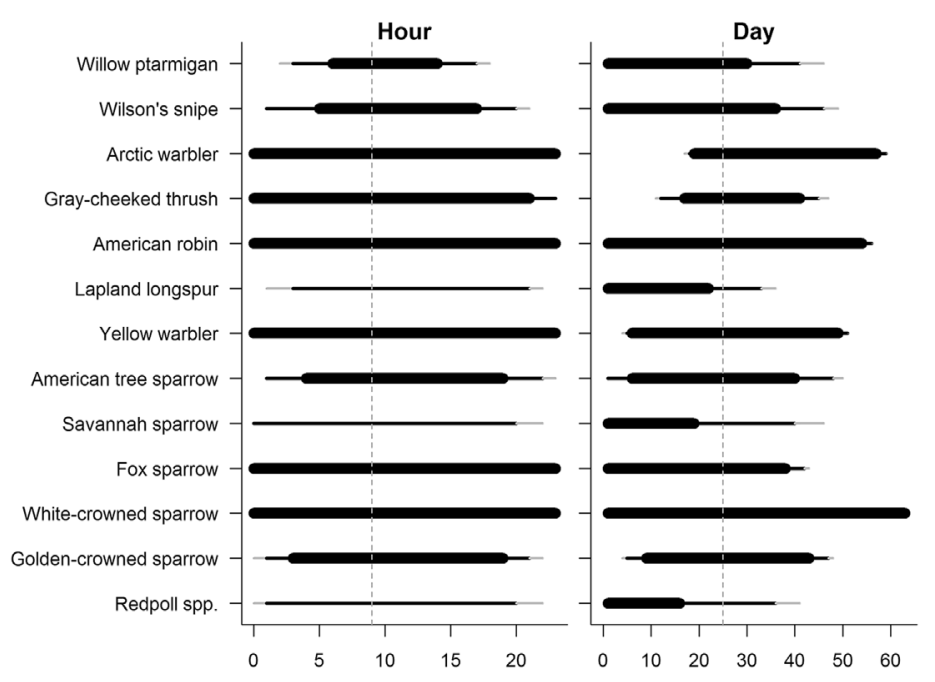

Figure 5. Model-based predictions of availability $\left(\mathrm{P}_{\mathrm{a}}\right)$, the probability that a bird species would vocalize at least once during a 10-minute survey in May-July, northwestern Alaska, USA, given it was present at a site, plotted as a function of hour of day (left panel) and day of season (right panel; day $1=25 \mathrm{May}$ ). Predictions are based on time-removal analysis of the timing of its vocalizations recorded within a 10-minute period. For predictions by hour, date was held constant at day 25 (18 Jun); for predictions by day of season, time was held constant at 0900 hours. Line color and width indicate predicted availability over the corresponding dates and times of day: thick black line $>99 \%$, thin black line 90-99\%, gray line 70-89\%, and no line $<70 \%$. Vertical lines show values selected for prediction (i.e., hr was fixed at 0900 to show variation in availability by day).

territories that overlapped considerably with areas well sampled by recorders (Nichols et al. 2009). Species that were detected infrequently may have represented birds that were singing less often (low $\mathrm{P}_{\mathrm{a}}$ ), or individuals with a low $\mathrm{P}_{\mathrm{p}}$, e.g., individuals with a territory that only partially overlapped the area sampled by the recording device (Nichols et al. 2009). We would predict that species with large breeding territories would more commonly display a pattern of periodic but infrequent site use, resulting from movement around large territories. This appeared to be the case with our data; species that demonstrated this pattern were long-tailed jaeger (Stercorarius longicaudus), American golden-plover (Pluvialis dominica), Canada goose (Branta canadensis), common raven (Corvus corax), and Pacific golden-plover (Pluvialis fulva). All of these species were observed at 10 or 11 sites, but in $7-10$ of these instances they were detected on $<5 \%$ of recordings. Other studies reported that density and occupancy for birds with relatively large territories were poorly estimated using point-count methods (Toms et al. 2006, Hayes and Monfils 2015).

Some species were detected rarely at a site in a given year, in many cases only once during dozens of hours of recordings. These instances are not to be confused with regionally rare birds; often a species that was detected consistently at 1 study site was considered rare at a different site (e.g., arctic warblers were observed frequently at 1 site, commonly at 2 , infrequently at 2, and rarely at 1 site; Fig. 6). We hypothesized that these rare instances might have been more common early or late in the breeding season, when birds were still arriving and establishing territories or during post-breeding dispersal periods (Pagen et al. 2000), but this was true for only a small number of species and sites. For the most part, observations of rarely detected species occurred throughout surveyed dates. The frequency of these instances highlights the lack of closure at each survey location (Bailey et al. 2014, Hayes and Monfils 2015). It also highlights the importance of distinguishing between instantaneous and asymptotic occupancy at a given site during a season, and how size of the sampling plot relative to size of the home range or territory can influence estimates of occupancy for mobile animals (Efford and Dawson 2012). If we examine the number of species detected rarely $(<5 \%$ of recordings) compared to those detected more often ( $\geq 5 \%$ of recordings), our data show that only $19-55 \%$ of species detected at a site would qualify as regular users of that site. Systematic use of acoustic recorders throughout a study area could thus assist in discerning such patterns and developing definitions of site use applicable to the species and questions of interest.

Our original intent was to interpret patterns of detections (as analyzed with GAMs) as $\mathrm{P}_{\mathrm{a}}$ at each site where the species was a known occupant (i.e., omitting sites where the species was never or rarely detected). However, detectability measured through repeated sampling with acoustic recorders is the joint probability $\mathrm{P}_{\mathrm{p}} \times \mathrm{P}_{\mathrm{a}} \times \mathrm{P}_{\mathrm{d}}$ for the superpopulation of birds ever using the sampling area during the season, and a number of nuisance factors, in addition to movement, were likely influencing $\mathrm{P}_{\mathrm{p}}$ and $\mathrm{P}_{\mathrm{d}}$. Repeated acoustic recordings are unsuitable for use in estimation of density because of the undefined areas and populations being sampled. An issue with acoustic recordings is that the shape and size of the recording area can be affected by a number of uncontrollable factors that influence the strength of the sound signal reaching the recorder (e.g., wind, vegetation, humidity, varying bird song volume; Hobson et al. 2002). Although we did not measure how such factors may have influenced the size and shape of the acoustical sampling area, we did 

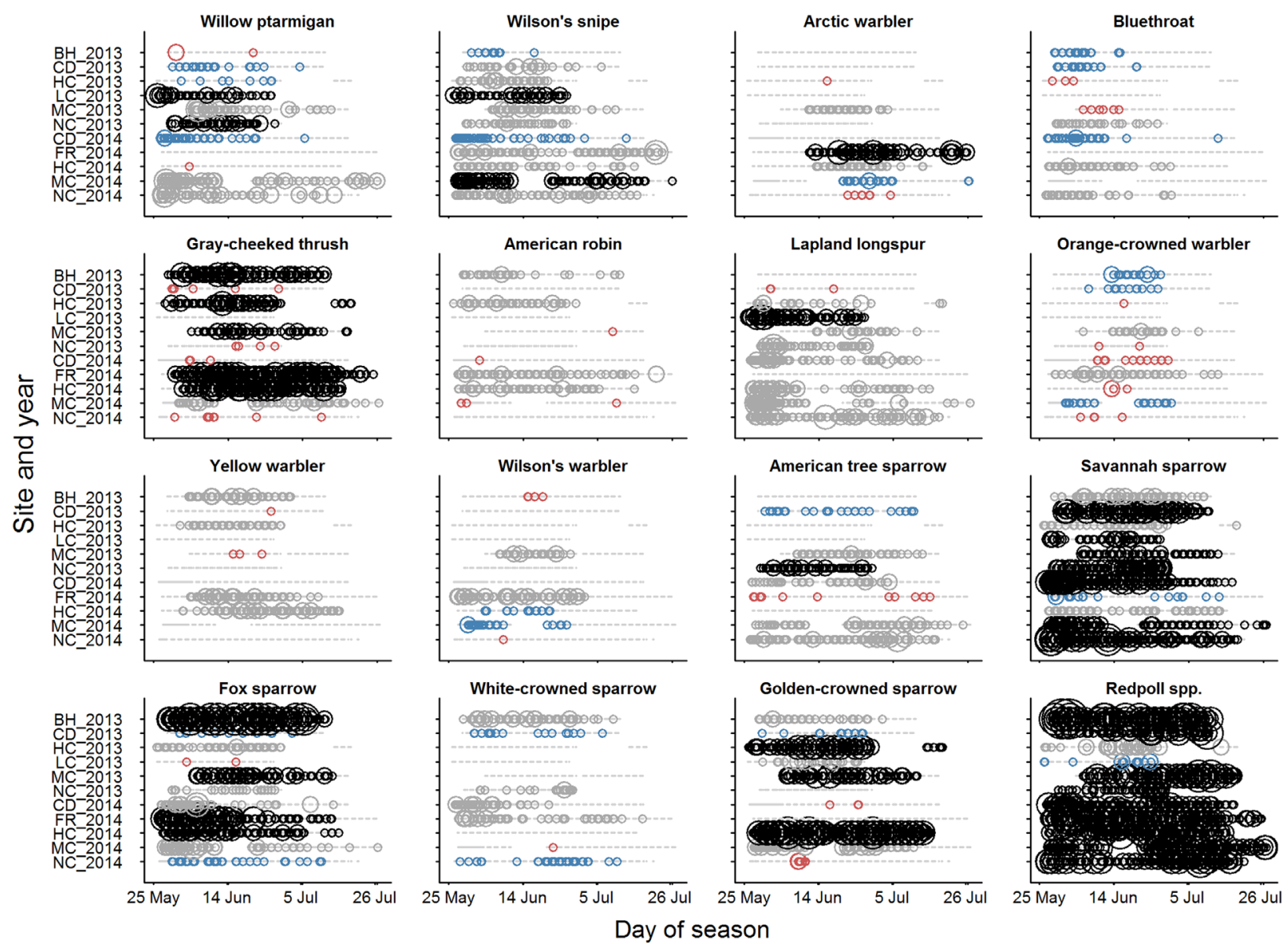

Figure 6. Temporal frequency of detections on 10-minute acoustic recordings by site for 16 species of commonly detected birds in May-July, northwestern Alaska, USA. Each circle represents a single 10-minute survey ( $x$-axis is by minute, so $>1$ recording/day would be distinct) and symbol sizes represent the total number of individuals detected on a recording (scaled for readability to 1,2 , or $\geq 3$ ). Colors indicate the category for frequency of detection at a given site and year: red $=$ rare $(0-5 \%$ of total recordings at the site), gray $=$ infrequent $(6-15 \%)$, light blue $=$ common $(16-50 \%)$, and black $=$ frequent $(>50 \%)$. For analyses, species that were rarely detected (red symbols in this figure) at a site during a year were considered non-users and were omitted. Vertical axis is labeled by siteyear. Pale gray dashes show when recordings occurred.

determine in an ancillary study that throughout the season most of the birds detected by the acoustic recorders were within $100 \mathrm{~m}$ (Vold et al. 2017). Thus, the effective sampling area of the recorder was small relative to the territory size of many of the larger-bodied avian species. As a result, the criterion we used to define a site user (hence $\mathrm{P}_{\mathrm{s}}$ ) was highly influential in estimating $\mathrm{P}_{\mathrm{p}}$ and $\mathrm{P}_{\mathrm{a}}$. When examining overall detection probabilities, we selected a threshold of $\geq 5 \%$ occurrence on recordings at a given site for a species to be considered a user so as to minimize the inclusion of migrants or other individuals with tenuous connections to breeding areas. If we had defined an occupied site more strictly and only included sites where a species was more ubiquitous in our analysis, our predicted detection probability would have concomitantly increased. The relative circadian and seasonal patterns of detection, however, would have not been fundamentally altered.

We did find that some species arrived late in spring and that systematic acoustic recordings can be used to identify appropriate starting survey dates, free from biases associated with observer variation. Tundra-breeding birds settled on territories and began singing ardently almost immediately upon arrival; thus, simply dropping surveys that took place before the first detection is a straightforward solution for analysis of late-arriving species (Kéry et al., 2005). Finally, a general assumption when conducting wildlife surveys is that conducting repeated or longer surveys will lead to the detection of a greater proportion of true site-using species. Our data suggest that a majority of species' detections will occur in the first minutes of a recording. This indicates that it might be more useful to take shorter recordings at more frequent intervals. Diefenbach et al. (2007) used detailed observations of focal bird activity to estimate $\mathrm{P}_{\mathrm{a}}$ for 2 grassland passerine species. Based only on audible cues, their estimates for availability during a 10-minute point count were considerably lower than ours, as estimated by removal models; for observations carried out during peak breeding season and between 0600 hours and 1000 hours, they estimated that $\mathrm{P}_{\mathrm{a}}$ was $0.435 \pm 0.0253$ for Henslow's sparrow (Ammodramus henslowii) and $0.211 \pm 0.0412$ for grasshopper sparrow (Ammodramus savannarum). Several elements are likely leading to the difference between our 
estimates and theirs. Our analysis examined availability at a species level, and thus would likely be much higher than availability for individual singing males. Second, because many birds likely sing in bursts and then are silent for periods of time, removal models may generally overestimate availability for birds that sing in these types of bursts (Diefenbach et al. 2007).

Our data also indicate that up to $55 \%$ of species that could be observed on our sites were potentially not true occupants, depending on how one defines a site occupant, particularly relative to the small area effectively surveyed by an acoustic recorder. Thus, additional sampling effort may introduce bias if interpreting patterns that result from exceedingly rare site users (Bonthoux and Balent 2011). Multi-species bird surveys may be particularly challenged in this regard; our results suggest that it would be difficult to optimize survey unit area, survey duration, time of day, and time of season for a suite of species with variable arrival dates, peak availability times, and territory sizes. Systematic acoustic recordings across a study area, however, provide a wealth of data that can be analyzed to determine how best to interpret data from a more spatially extensive but less temporally intensive set of surveys across the landscape.

\section{MANAGEMENT IMPLICATIONS}

At high latitudes, many species of birds are consistently available for detection into afternoon or evening hours. We suggest that researchers at high latitudes, depending on their species of interest, can realistically conduct avian occupancy surveys until as late as 2000 hours, and should specifically avoid surveying between 2200 hours and 0500 hours. In our subarctic tundra study area, most species were highly detectable shortly after arrival and detection dropped sharply later in the season, around 4 July for many species, indicating that careful survey timing or data truncation are critical for studies of avian occupancy. Our results also suggest that for most species of birds, a single 10-minute survey during times and dates of high availability is likely sufficient to establish occupancy status. However, because of seasonal discrepancies in peak detectability between earlyand late-arriving species, 2 surveys may be useful. Systematic acoustic recordings can serve to establish seasonal and diurnal periods of peak availability and to identify those species that are serendipitous site users. We suggest that, in some instances, minimum inclusion criteria might be useful for defining a site user. For example, if a species is detected on $<5 \%$ of recordings, it may be beneficial to exclude that species from further analyses, depending on the purpose of the study. Additionally, when processing audio recordings, we found that in any single 10-minute recording, the majority of species detected were noted within the first several minutes; thus, species that are present and available tend to be highly detectable during a discrete time interval and more frequent, shorter duration recordings might be a more efficient way to detect more species.

\section{ACKNOWLEDGMENTS}

Any use of trade names in this publication is for descriptive purposes only and does not imply endorsement by the U.S.
Government. We thank S. T. Vold for help conducting surveys and many long hours interpreting the recordings. We also thank R. M. Richardson and J. Terenzi for assistance in the field. C. L. Amundson, D. H. Johnson, and 2 anonymous reviewers provided constructive comments on the manuscript. This work is part of the U.S. Geological Survey (USGS) Changing Arctic Ecosystems Initiative, supported by the Wildlife Program of the USGS Ecosystems Mission Area.

\section{LITERATURE CITED}

Acevedo, M. A., and L. J. Villanueva-Rivera. 2006. Using automated digital recording systems as effective tools for the monitoring of birds and amphibians. Wildlife Society Bulletin 34:211-214.

Alldredge, M. W., K. Pacifici, T. R. Simons, and K. H. Pollock. 2008. A novel field evaluation of the effectiveness of distance and independent observer sampling to estimate aural avian detection probabilities. Journal of Applied Ecology 45:1349-1356.

Ammon, E. M., and W. M. Gilbert. 1999. Wilson's warbler (Cardellina pusilla). Account 478 in P. G. Rodewald, editor. The birds of North America. Cornell Lab of Ornithology, Ithaca, New York, USA.

Amundson, C. L., J. A. Royle, and C. M. Handel. 2014. A hierarchical model combining distance sampling and time removal to estimate detection probability during avian point counts. Auk: Ornithological Advances 131:476-494.

Ashley, N. T., I. Schwabl, W. Goymann, and C. L. Buck. 2013. Keeping time under the midnight sun: behavioral and plasma melatonin profiles of free-living Lapland longspurs (Calcarius lapponicus) during the Arctic summer. Journal of Experimental Zoology Part A: Ecological Genetics and Physiology 319:10-22.

Bailey, L. L., D. I. MacKenzie, and J. D. Nichols. 2014. Advances and applications of occupancy models. Methods in Ecology and Evolution 5:1269-1279.

Bonthoux, S., and G. Balent. 2011. Point count duration: five minutes are usually sufficient to model the distribution of bird species and to study the structure of communities for a French landscape. Journal of Ornithology 153:491-504.

Brewster, J. P., and T. R. Simons. 2009. Testing the importance of auditory detections in avian point counts. Journal of Field Ornithology 80:178-182.

Buckland, S. T., D. R. Anderson, K. P. Burnham, and J. L. Laake. 1993. Distance sampling: estimating abundance of biological populations. Chapman and Hall, London, United Kingdom.

Dail, D., and L. Madsen. 2011. Models for estimating abundance from repeated counts of an open metapopulation. Biometrics 67:577-587.

Diefenbach, D. R., D. W. Brauning, and J. A. Mattice. 2003. Variability in grassland bird counts related to observer differences and species detection rates. Auk 120:1168-1179.

Diefenbach, D. R., M. R. Marshall, J. A. Mattice, and D. W. Brauning. 2007. Incorporating availability for detection in estimates of bird abundance. Auk 124:96-106.

Efford, M. G., and D. K. Dawson. 2012. Occupancy in continuous habitat. Ecosphere 3:1-15.

Farnsworth, G. L., K. H. Pollock, J. D. Nichols, T. R. Simons, J. E. Hines, and J. R. Sauer. 2002. A removal model for estimating detection probabilities from point-count surveys. Auk 119:414-425.

Fiske, I., and R. Chandler. 2011. unmarked: an R package for fitting hierarchical models of wildlife occurrence and abundance. Journal of Statistical Software 43:1-23.

Guillera-Arroita, G., J. J. Lahoz-Monfort, D. I. MacKenzie, B. A. Wintle, and M. A. McCarthy. 2014. Ignoring imperfect detection in biological surveys is dangerous: a response to "fitting and interpreting occupancy models." PLoS ONE 9:e99571.

Hayes, D. B., and M. J. Monfils. 2015. Occupancy modeling of bird point counts: implications of mobile animals. Journal of Wildlife Management 79:1361-1368.

Hobson, K. A., R. S. Rempel, H. Greenwood, B. Turnbull, and S. L. Van Wilgenburg. 2002. Acoustic surveys of birds using electronic recordings: new potential from an omnidirectional microphone system. Wildlife Society Bulletin 30:709-720.

Kéry, M., and J. A. Royle. 2015. Applied hierarchical modeling in ecology: analysis of distribution, abundance and species richness in R and BUGS. 
Volume 1: prelude and static models. Academic Press, San Diego, California, USA.

Kéry, M., J. A. Royle, and H. Schmid. 2005. Modeling avian abundance from replicated counts using binomial mixture models. Ecological Applications 15:1450-1461.

Kessel, B. 1989. Birds of the Seward Peninsula, Alaska. First edition. University of Alaska Press, Fairbanks, USA.

Latif, Q. S., M. M. Ellis, and C. L. Amundson. 2015. A broader definition of occupancy: comment on Hayes and Monfils. Journal of Wildlife Management 80:192-194.

Lee, D. C., and S. J. Marsden. 2008. Adjusting count period strategies to improve the accuracy of forest bird abundance estimates from point transect distance sampling surveys. Ibis 150:315-325.

Lein, M. R. 2007. Patterns of dawn singing by buff-breasted flycatchers. Journal of Field Ornithology 78:343-351.

Lowther, P. E., C. Celada, N. K. Klein, C. C. Rimmer, and D. A. Spector. 1999. Yellow warbler (Dendroica petechia). Account 454 in P. G. Rodewald, editor. The birds of North America. Cornell Lab of Ornithology, Ithaca, New York, USA.

Lynch, J. R. 1995. Effects of point count duration, time-of-day, and aural stimuli on detectability of migratory and resident bird species in Quintana Roo, Mexico. Pages 1-6 in C. J. Ralph, J. R. Sauer, and S. Droege, editors. Monitoring bird populations by point counts. USDA Forest Service General Technical Report PSW-GTR-149, Berkeley, California, USA.

MacKenzie, D. I., J. D. Nichols, G. B. Lachman, S. Droege, J. A. Royle, and C. A. Langtimm. 2002. Estimating site occupancy rates when detection probabilities are less than one. Ecology 83:2248-2255.

MacKenzie, D. I., and J. A. Royle. 2005. Designing occupancy studies: general advice and allocating survey effort. Journal of Applied Ecology 42:1105-1114.

McShea, W. J., and J. H. Rappole. 1997. Variable song rates in three species of passerines and implications for estimating bird populations. Journal of Field Ornithology 68:367-375.

Miller, D. A., J. D. Nichols, B. T. McClintock, E. H. C. Grant, L. L. Bailey, and L. A. Weir. 2011. Improving occupancy estimation when two types of observational error occur: non-detection and species misidentification. Ecology 92:1422-1428.

Nebel, S., and B. J. McCaffery. 2003. Vocalization activity of breeding shorebirds: documentation of its seasonal decline and applications for breeding bird surveys. Canadian Journal of Zoology 81:1702-1708.

Nichols, J. D., J. E. Hines, J. R. Sauer, F. W. Fallon, J. E. Fallon, and P. J. Heglund. 2000. A double-observer approach for estimating detection probability and abundance from point counts. Auk 117:393-408.

Nichols, J. D., L. Thomas, and P. B. Conn. 2009. Inferences about landbird abundance from count data: recent advances and future directions. Pages 201-235 in D. L. Thomson, E. G. Cooch, and M. J. Conroy, editors. Modeling demographic processes in marked populations. Springer, New York, New York, USA.

Pagen, R. W., F. R. Thompson III, and D. E. Burhans. 2000. Breeding and post-breeding habitat use by forest migrant songbirds in the Missouri Ozarks. Condor 102:738-747.

Pereyra, M. E. 2011. Effects of snow-related environmental variation on breeding schedules and productivity of a high-altitude population of dusky flycatchers (Empidonax oberholseri). Auk 128:746-758.

Pollock, K. H., J. D. Nichols, T. R. Simons, G. L. Farnsworth, L. L. Bailey, and J. R. Sauer. 2002. Large scale wildlife monitoring studies: statistical methods for design and analysis. Environmetrics 13:105-119.

R Development Core Team. 2015. R: a language and environment for statistical computing. R Foundation for Statistical Computing, Vienna, Austria.

Ralph, C. J., J. R. Sauer, and S. Droege, editors. 1998. Monitoring bird populations by point counts. USDA Forest Service General Technical Report PSW-GTR-149, Berkeley, California, USA.

Rempel, R. S., K. A. Hobson, G. Holborn, S. L. Van Wilgenburg, and J. Elliott. 2005. Bioacoustic monitoring of forest songbirds: interpreter variability and effects of configuration and digital processing methods in the laboratory. Journal of Field Ornithology 76:1-11.

Robbins, C. S. 1981. Effect of time of day on bird activity. Studies in Avian Biology 6:275-286.

Rollfinke, B. F., and R. H. Yahner. 1990. Effects of time of day and season on winter bird counts. Condor 92:215-219.

Royle, J. A. 2004. N-mixture models for estimating population size from spatially replicated counts. Biometrics 60:108-115.

Royle, J. A., and J. D. Nichols. 2003. Estimating abundance from repeated presence-absence data or point counts. Ecology 84:777-790.

Sauer, J. R., B. G. Peterjohn, and W. A. Link. 1994. Observer differences in the North American Breeding Bird Survey. Auk 111:50-62.

Schieck, J. 1997. Biased detection of bird vocalizations affects comparisons of bird abundance among forested habitats. Condor 99:179-190.

Sidie-Slettedahl, A. M., K. C. Jensen, R. R. Johnson, T. W. Arnold, J. E. Austin, and J. D. Stafford. 2015. Evaluation of autonomous recording units for detecting three species of secretive marsh birds. Wildlife Society Bulletin 39:626-634.

Silverin, B., E. Gwinner, T. J. Van't Hof, I. Schwabl, L. Fusani, M. Hau, and B. Helm. 2009. Persistent diel melatonin rhythmicity during the Arctic summer in free-living willow warblers. Hormones and Behavior 56:163-168

Simons, T. R., M. W. Alldredge, K. H. Pollock, and J. M. Wettroth. 2007. Experimental analysis of the auditory detection process on avian point counts. Auk 124:986-999.

Skirvin, A. A. 1981. Effect of time of day and time of season on the number of observations and density estimates of breeding birds. Studies in Avian Biology 6:271-274.

Smith, P. A., H. G. Gilchrist, M. R. Forbes, J.-L. Martin, and K. Allard. 2010. Inter-annual variation in the breeding chronology of arctic shorebirds: effects of weather, snow melt and predators. Journal of Avian Biology 41:292-304.

Steiger, S. S., M. Valcu, K. Spoelstra, B. Helm, M. Wikelski, and B. Kempenaers. 2013. When the sun never sets: diverse activity rhythms under continuous daylight in free-living arctic-breeding birds. Proceedings of the Royal Society of London B: Biological Sciences 280:20131016.

Thompson, S. J., C. M. Handel, R. M. Richardson, and L. B. McNew. 2016. When winners become losers: predicted nonlinear responses of arctic birds to increasing woody vegetation. PLoS ONE 11: e0164755.

Toms, J. D., F. K. A. Schmiegelow, S. J. Hannon, and M.-A. Villard. 2006. Are point counts of boreal songbirds reliable proxies for more intensive abundance estimators? Auk 123:438-454.

Vold, S. T., C. M. Handel, and L. B. McNew. 2017. Comparison of acoustic recorders and field observers for monitoring tundra bird communities. Wildlife Society Bulletin 41:in press.

Welsh, A. H., D. B. Lindenmayer, and C. F. Donnelly. 2013. Fitting and interpreting occupancy models. PLoS ONE 8:e52015.

Wilson, D. M., and J. Bart. 1985. Reliability of singing bird surveys: effects of song phenology during the breeding season. Condor 87:69-73.

Wood, S. 2016. mgcv: Mixed GAM computation vehicle with GCV/AIC/ REML smoothness estimation. Version 1. 8-9. https://cran.r-project.org/ web/packages/mgcv/index.html. Accessed 09 Feb 2016.

Zuur, A. F., E. N. Ieno, and G. M. Smith. 2007. Analysing ecological data. Springer, New York, New York, USA.

Associate Editor: Frank Thompson.

\section{SUPPORTING INFORMATION}

Additional supporting information may be found in the online version of this article at the publisher's website. 